\title{
Psicanálise com crianças: Quando o brincar é dizer.
}

\author{
Katlyn Regina Lopes ${ }^{1}$
}

\begin{abstract}
Era uma casa muito engraçada Não tinha teto / Não tinha nada Ninguém podia entrar nela não Porque na casa não tinha chão Ninguém podia dormir na rede Porque na casa não tinha parede

Ninguém podia fazer pipi

Porque pinico não tinha ali Mas era feita com muito esmero Na rua dos bobos número zero Mas era feita com muito esmero

$\mathrm{Na}$ rua dos bobos número zero

A Casa, Vinícius de Moraes
\end{abstract}

Resumo: Esse trabalho discorrerá acerca de um estudo teórico, uma revisão bibliográfica sobre o brincar e sua função no processo psicanalítico da criança. Será apresentado em dois capitulos. O primeiro capitulo fará alusão a história da psicánalise com crianças, abordando três autores. Começando com Freud e o inicio da abordagem da criança pela psicanálise. O segundo autor a seu abordado é Anna Freud com sua visão pedagógica da psicanálise e em seguida Melanie Klein com sua técnica do brincar é estuda. No segundo capitulo será trabalhado o brincar e sua função na prática psicanalítica com crianças Finalizando o trabalho serão feitas considerações finais e a conclusão.

\section{Introdução e Objetivos}

No pequeno trecho da canção "A Casa”, apresentada no inicio desse trabalho, Vinícius de Moraes nos traz a descrição de um local, mais especificamente citado por ele como uma casa. Uma casa que lhe parece ser estranha, até o momento desconhecida e engraçada como ele mesmo poetiza. Essa casa é reconhecida por ele como tal mesmo ele não encontrando nela as

\footnotetext{
${ }^{1}$ Graduada em Psicologia pela UFPR.
} 
características básicas que ele mesmo convencionou que uma casa deveria ter. A casa não tinha um teto, nem paredes e muito menos um pinico. Nem endereço possível de acesso essa casa tem e, apesar disso, ela existe e se faz presente sendo "feita com muito esmero".

$\mathrm{O}$ que acontece quando reconhecemos um lugar, como faz o autor da canção, sabemos que lugar é esse e, no entanto, esse lugar se apresenta engraçado ou estranho? Como um lugar diferente da imensidade de registros que possuímos, ou que nos possuem, e que fundamentam as nossas convenções de como esse lugar deveria ser, ou de como desejaríamos que ele seja?

A casa não tinha parede e por isso o desejo de pendurar uma rede não era possível. Não se podia fazer pipi, mesmo que se quisesse muito, pois na casa não havia pinico.

A proposta deste trabalho gira em torno psicanálise com crianças e se trata mais especificamente da investigação sobre o brincar na prática clínica com crianças.

Quando comecei a pensar esse trabalho a primeira questão que foi levantada por mim é no que consiste a psicanálise de crianças ou do que estamos falando quando nos referimos a uma psicanálise infantil e quais as suas características?. Como na canção, "A Casa" de Vinícius de Moraes, a Psicanálise com crianças se apresenta para mim ainda engraçada, sem teto, sem chão e sem pinico.

Essa questão surgiu partindo da seguinte situação: $\mathrm{Na}$ Universidade, em que estudo, mais especificamente no curso de psicologia, no quarto ano da graduação iniciam-se três disciplinas de estágios que tem por objetivo preparar o alunos para as escolhas dos estágios de final de curso que ocorrerão no decorrer de todo o último ano do curso. Entre a ocorrência de conversas entre os colegas de curso sobre essas escolhas já pensando em escolhas futuras para o quinto e ultimo ano.

Bem, durante essas corriqueiras conversas continuamente eu apresentava a minha vontade de cursar o estágio de clínica em uma abordagem psicanalítica e no atendimento de crianças. Foi possível notar no desenvolver da minha curiosidade sobre o assunto que da oferta de professores, nessa instituição de ensino, que supervisionem em psicanálise apenas uma oferece supervisão no atendimento de crianças. Fui perguntar, então, a um desses supervisores, de abordagem psicanalítica, o porque não oferecia esse tipo de supervisão e fiquei intrigada com a sua resposta ao relatar que esse assunto não fazia parte de fazia parte de seu cotidiano e o atendimento de crianças lhe incomodava. 
Com a curiosidade mais aguçada realizei uma pequena pesquisa em um site de busca na Internet e rapidamente foi possível notar uma distinta separação, nos autores que estudam o assunto, entre a Psicanálise e a Psicanálise infantil.

"A psicanálise de crianças é a psicanálise" relatou Freud, em 1909, quando se ocupava com a analise de um caso de fobia de um garoto de cinco anos, o Pequeno Hans. Essa afirmação freudiana me colocou a pensar o porque a psicanálise de crianças é a psicanálise?

Na psicanálise de Freud e também a de Lacan o campo em que o analista opera é o da linguagem e existe o grande interesse pelo infantil ou ainda pela sexualidade infantil. E então por que a psicanálise de crianças não seria a psicanálise? Ou apenas ser considerada como uma psicanálise com crianças?

No entanto, tenho ainda muita dificuldade para visualizar um pouco do que poderiam significar essas perguntas se meus conhecimentos sobre a psicanálise infantil, como já mencionei anteriormente, são estranhos e longe dos registros que possuo da psicanálise e mais ainda com relação a crianças.

Deixando essas várias perguntas momentaneamente de lado parti então para uma questão mais especifica que equivale a investigar de onde surgiu a prática clinica com crianças. Qual a sua história? E uma de suas caracteristica principais, que proporciona umas das distinções entre as duas práticas - a com crianças e a com adultos - a técnica do brincar e sua função também será explorada neste trabalho.

\section{História da psicanálise com crianças:}

\subsection{Freud: o início}

A psicanálise com crianças foi abordada por Freud inicialmente em seu texto $^{2}$ de 1909, o "Pequeno Hans", que se trata da analise feita por ele da fobia de uma criança de cinco anos. Essa obra pode ser considerada a base para a compreensão da psicanálise de crianças mas a sua história começou a tomar forma pouco tempo antes.

Partindo da clínica com adultos e de seu interesse pelos distúrbios nervosos a psicanálise surgiu com os trabalhos iniciais de Sigmund Freud. Com o decorrer de seu percurso a teoria Freudiana amadureceu com o surgimento de seu interesse pelo sexual ou mais especificamente pelo sexual infantil. Porém desde o início de suas investigações Freud dava uma grande importância pelos efeitos dos fatos passados no presente de sues pacientes.

\footnotetext{
${ }^{2}$ Freud, Sigmund "Analise de uma fobia de um menino de cinco anos"
} 
Os primeiros descobrimentos de Freud são fundamentais para a compreensão do nascimento da psicanálise com crianças. A passagem feita por ele da técnica da sugestão e da hipnose para a associação livre foi, além de um marco na psicanálise, a efetivação de que os pacientes continuavam através de um livre-trânsito a falar e a recordar os traumas infantis.

A associação livre como nova prática adotada por Freud proporcionou uma valorização da relação paciente e terapeuta. Relação esta que se tornou um novo e importante agente ao qual ele denominou transferência.

Freud nas Conferências Introdutórias" relata que

"Nada acontece em um tratamento psicanalítico além de um intercâmbio de palavras entre o paciente e o analista. O paciente conversa, fala de suas experiências passadas e de suas impressões atuais, queixa-se, reconhece seus desejos e seus impulsos emocionais. O médico escuta, procura orientar os processos de pensamento do paciente, exorta, dirige sua atenção em certas direções, dá-lhe explicações e observa as reações de compreensão ou rejeição que ele, analista, suscita no paciente."

Ao psicanalista cabe escutar, paciente; ou, melhor dizendo, constituir sua escuta, como eu já disse anteriormente, no livre-trânsito pelo próprio inconsciente, criando desse modo condições para que algum lugar transferencial aconteça. E por ser assim, por ser essa a natureza dessa atividade, toda e qualquer modalidade de relação com o poder e com suas facetas mais sutis será traduzida, transferida, deslocada, retratada, na transferência. A relação que estabelecemos com a teoria está ali, com os colegas, está ali, com as instituições, ali, presentificada com todas as vírgulas, aspas, reticências e pontos de exclamação.

$\mathrm{Na}$ pratica clinica, Freud coloca que é possível observar que a transferência tem sua base na infância e o paciente apenas representava no terapeuta as suas primeiras relações de objeto.

Em mais além do principio do prazer, tópico III

"Essas reproduções, que surgem com tal exatidão indesejada, sempre têm como tema alguma parte da vida sexual infantil, isto é, do complexo de Édipo, e de seus derivativos, e são invariavelmente atuadas (acted out) na esfera da transferência, da relação do paciente com o médico. Quando as coisas atingem essa etapa, pode-se dizer que a neurose primitiva foi então substituída por outra nova, pela 'neurose de transferência'. O médico empenha-se por manter essa neurose de transferência dentro dos limites mais restritos; forçar tanto quanto possível o canal da memória, e permitir que surja como repetição o mínimo possível. A proporção entre o que é lembrado e o que é reproduzido varia de 
caso para caso. O médico não pode, via de regra, poupar ao paciente essa face do tratamento."

Freud percebeu que com o tempo e partindo do método da associação livre e da relação transferencial é possível realizar a passagem de alguns conteúdos aos pacientes, em momentos oportunos, fazer algumas pontuações ou interpretações, para realizar a passagem dos conteúdos inconscientes para o consciente.

A descoberta da linguagem do inconsciente, de seu sentido, feita por Freud proporcionou a necessidade de conhecer o que não esta à superfície do sujeito. Decifrar a linguagem do inconsciente passa a ser um dos objetivos da psicanálise. Esse objetivo é conseqüência não apenas de uma demanda freudiana e sim também de uma demanda do sujeito da psicanálise.

A necessidade de uma metodologia tendo em vista esse objetivo, que foi construído a partir de uma atividade, deve-se construir da mesma maneira, ou seja, em conseqüência das demandas.

O trabalho da psicanálise se constitui através de interpretações do sentido dos materiais trazidos pelo sujeito que manifestam o inconsciente e que permitem não apenas conferir a linguagem existente, mas que trazem elementos que ajudem o analista a elaborar uma decriptação - como afirma Foucalt - desta linguagem.

Para considerar a linguagem do inconsciente, é necessário não ignorar a historicidade do sujeito que fala. A psicanálise estuda assim as manifestações da linguagem inconsciente no passado que ainda atua, ou melhor fala, através do sentido da conduta atual.

Neste sentido o passado se presentifica constantemente e entender o sentido desse mecanismo possibilita uma significação do que se mantinha inalterado com o passar do tempo. E é ai, na possibilidade desta significação, que aparece a eficácia da interpretação.

É importante salientar que através do método da Associação Livre, transferência e da interpretação é possível reparar a presença onipotente desse passado constante e com ele concomitantemente a da infância.

$\mathrm{O}$ estudo da histeria, que toma grande parte da obra freudiana já que seus primeiros escritos de psicanálise se interessavam pela etiologia das neuroses, justifica essa grande preocupação com a infância.

Freud ficou impressionado ao pensar em como acontecimentos de tão longa data poderiam ainda causar sofrimento e de maneira intensa. E o porque dessas lembrança ao mesmo tempo em que se fazem presente estão de certa forma obscuras para o ego e presentes no inconsciente. 
A celebre frase de Freud e Breuer de 1893 "Os histéricos sofrem principalmente de reminiscências" (inicio do tópico I em, sobre o mecanismo psíquico dos fenômenos histéricos: comunicação preliminar, em 1893), foi uma descoberta importante para as obras posteriores.

Similar a um processo de escavação arqueológico, a psicanálise se compromete a investigar as profundezas do inconsciente de maneira devagar, para não perder parte do conteúdo, passar pelas camadas do sintoma mesmo que em um primeiro momento o interesse é apenas saber o que tem ali. O sentido do achado aparece posteriormente através da relação com os outros achados que provavelmente se encontram mais ocultos.

Para entender melhor a importância da sexualidade infantil, no decorrer do percurso da prática psicanalítica e o por que ela vai ocupando o papel central. Faz-se necessário passar por toda a reconstituição do tenro início da psicanálise.

Posteriormente em o pequeno Hans Freud, pela primeira vez se propôs a fazer a analise de uma criança. Ele executou a analise de forma não habitual da psicanálise pois ele viu somente uma vez o paciente. Foi uma exceção letrada por Freud já que no caso não existia a relação terapeuta-paciente, ou a indispensável relação transferencial, considerada pela psicanálise como um elemento básico na prática clínica.

Hans foi analisado através de seu pai que mantinha um contato constante com Freud. Como ele mesmo relata

"O caso clínico, estritamente falando, não provém de minha própria observação. É verdade que assentei as linhas gerais do tratamento e que numa única ocasião, na qual tive uma conversa com o menino, participei diretamente dele; no entanto, o próprio tratamento foi efetuado pelo pai da criança, sendo a ele que devo meus agradecimentos mais sinceros por me permitir publicar suas observações acerca do caso. Todavia, sua ajuda ultrapassa esta contribuição. Ninguém mais poderia, em minha opinião, ter persuadido a criança a fazer quaisquer declarações como as dela; o conhecimento especial pelo qual ele foi capaz de interpretar as observações feitas por seu filho de cinco anos era indispensável; sem ele as dificuldades técnicas no caminho da aplicação da psicanálise numa criança tão jovem como essa teriam sido incontornáveis. Só porque a autoridade de um pai e a de um médico se uniam numa só pessoa, e porque nela se combinava o carinho afetivo com o interesse científico, é que se pôde, neste único exemplo, aplicar o método em uma utilização para a qual ele próprio não se teria prestado, fossem as coisas diferentes. "(Freud,1909)

Partindo desse caso clínico Freud pode chegar a duas observações distintas: a primeira remete a relação paciente e terapeuta que para ele é o que 
permite o significado da interpretação da transferência que é a união da figura do terapeuta com o objeto originário e a segunda consiste na importância da afirmação de que terapia e investigação são inseparáveis em psicanálise.

A teoria sexual infantil Freudiana até então só havia sido estudada em adultos. Com o método da cura de uma neurose infantil pode comprovar os seus postulado sobre o complexo de Édipo partindo da observação.

"No começo, minhas declarações sobre a sexualidade infantil basearamse quase exclusivamente nos achados, da análise de adultos, que remontavam o passado. Não tive nenhuma oportunidade de fazer observações diretas em crianças. Foi portanto uma grande vitória quando, anos depois, tornou-se possível confirmar quase todas as minhas deduções através da observação direta e da análise de crianças muito pequenas...Quanto mais se levasse adiante as observações em crianças, mais evidentes os fatos se tornavam; porém o mais surpreendente de tudo era constatar que tivesse havido tanta preocupação em menosprezalas.” (Freud, p. 28,1914)

Esse é apenas o começo da psicanálise com crianças. Freud deu apenas a largada e a corrida foi disputada por alguns de seus seguidores.

\section{2 - Anna Freud: a psicanálise como educativa.}

Dentre os participantes da corrida por uma abordagem infantil da psicanálise se faz presente e concorrente Anna Freud, filha casula de Sigmund Freud.

Anna Freud se dedicou durante grande parte de sua vida a psicanálise, seguindo os passos de seu tão famoso pai, dando uma maior ênfase a psicanálise com crianças, seus escritos e postulados foram e ainda são de grande utilidade para a psicanálise além de pais e profissionais ligados a educação.

Concomitante com Klein, Anna foi uma das precursoras na psicanálise infantil e na época as discussões entre as duas correntes, kleiniana e annafreudianas, eram rotineiras.

Tanto Klein como Anna Freud não se afastam dos postulados Freudianos porém existem grandes diferenças entre as duas. As diferenças atuam principalmente no que diz respeito a teorias de formação de ego e do superego, relações transferências e objectais.

Anna Freud em sua prática clinica com crianças se utiliza da interpretação de sonhos, sonhos diurnos e de desenhos fazendo restrições do uso 
de jogos e brincadeiras. Para ela os sonhos infantis são mais fáceis de analise em comparação com os sonhos dos adultos. A criança expressa de um modo direto a realização de desejos. Com crianças maiores e com o ego e superego mais estruturados, os sonhos já se encontram deformados pela elaboração onírica. $\mathrm{O}$ jogo é utilizado pela psicanalista apenas como complemento a analise de sonhos ou desenhos.

Na clínica com crianças Anna Freud acredita em uma distinção existente em relação a psicanálise com adultos. Para ela a criança possui uma imaturidade que prejudica em muitos aspectos, qualitativamente falando o percurso de uma análise. Assim Anna Freud defende uma técnica de preparação de crianças, um trabalho prévio com as crianças, utilizando-se como exemplo comparativo a clinica com psicóticos, como Aberastury(1979: 44) comenta que "Para Anna Freud parte das dificuldades podem ser superadas coma realização de um trabalho prévio que coloque a criança em situação de enfrentar a análise".

Essa técnica, de uma preparação da criança para a situação de uma análise, esta ligada a um aspecto de grande importância e muito abordado por Anna Freud: a sua concepção de que a criança não reconhece que está enferma. Ela coloca que com esse desconhecimento não exista motivação para qualquer tipo de tratamento. Anna Freud afirma que "falta no quadro clínico tudo aquilo que parece indispensável no caso do paciente adulto: a consciência (insight) de enfermidade, a decisão e a vontade de curar-se". (1926: 22)

A falta de uma queixa da criança, para Anna Freud, é um dos empecilhos que prejudicam a analise com crianças e além disso é mais uma prova da diferença que existe em relação a prática clinica com adultos.

No entanto, Anna freud acredita haver um aspecto importante que dá uma grande motivação às crianças em relação ao tratamento psicanalítico, aspecto esse que torna possível a análise infantil:

"A ânsia de completar o desenvolvimento é incomensuravelmente mais poderosa no imaturo do que jamais poderá ser na vida adulta. A personalidade inacabada da criança se encontra em um estado fluido. Os sintomas que servem como solução de conflito em um nível de desenvolvimento provam ser inúteis no seguinte e são descartados. A libido e a agressão estão em constante movimento e mais do que no adulto a fluir no novos canais que foram abertos pela terapia". (1965: 31)

Nessa observação, evidencia-se a crença de Anna Freud em um ego inato. Assim, justifica-se a sua proposta de um trabalho analítico que tenha como objetivo o fortalecimento do ego do paciente, a fim de dar-lhe condições de fazer 
uma adaptação bem sucedida à realidade. Esse trabalho, por sua vez, implica um papel bem diretivo do analista.

Por não confiar na capacidade transferencial das crianças, Anna Freud propõe alguns procedimentos preliminares à análise, como já foi comentado anteriormente, com o intuito de criar uma transferência positiva e tornar possível o tratamento. Vale ressaltar que Sigmund Freud acreditava que a criança tinha capacidade para fazer transferência com seu pai, e assim a análise poderia ser realizada por ele. Essa, aliás, foi sua experiência com sua filha Anna e também com Hans quando se utilizou do pai do menino para a realização da análise.

Anna Freud propõe que se conscientize a criança de sua doença, bem como que lhe sejam proporcionada sentimentos de apego e confiança em relação à análise e ao analista: o principal cuidado aqui deve ser a instalação de um vínculo forte que livre o trabalho analítico da possibilidade de algum tipo de interrupção.

De fato, Anna Freud costuma lançar mão de todos os artifícios possíveis para criar na criança a confiança para a instalação de uma transferência positiva. A sua postura de não medir esforços para se adaptar a todos os caprichos da criança, fazendo crer que é imprescindível, e usando de toda a sedução possível para a criação de um vínculo forte, a coloca num lugar de absoluta idealização que parece não querer questionar, bastando-lhe a justificativa de que essa postura seria importante para salvar o tratamento da possibilidade de ser interrompido.

O analista, para Anna, representaria para a criança um novo personagem, um novo objeto no seu mundo junto aos pais, não se comportando como o adulto, que concentra a sua neurose no analista. Entretanto, o analista pode ser usado pelo paciente de múltiplas maneiras, pois a necessidade de novas experiências que a criança sente em relação ao analista seria tão forte quanto a "ânsia de repetir", que se manifesta na transferência. Mas se normalmente a criança lidaria com o analista como um novo objeto, o desenvolvimento neurótico altera esse equilíbrio; assim, a criança usará o analista como objeto de transferência, "na medida em que a sua neurose ou outros distúrbios interferirem".

Anna Freud chama a atenção para a dificuldade que o analista encontra para lidar com esta dupla relação instaurada pelo pequeno paciente: se o analista aceita o lugar de um novo objeto, diferente dos pais, interfere com as reações de transferência; se ignora ou rejeita esse aspecto, decepciona o paciente em suas esperanças.

A autora acredita, assim, na primordial necessidade que o analista tem de passar por um treino técnico cuidadoso para que possa administrar essa situação e ter condições de distinguir esses dois papéis. 
Por outro lado, a transferência seria difícil não somente pela estrutura da criança, mas também pela postura do próprio analista de crianças, a quem Anna Freud atribui objetivos pedagógicos. A associação dos objetivos pedagógicos e analíticos atrapalhariam a instalação da neurose de transferência, pois como a criança conhece seu analista mais de perto, tem uma idéia do que reprova e do que aceita, de como pensa, e de que valores tem.

Se concebemos o analista como uma pessoa com idéias e valores próprios que se manifesta sobre a educação da criança, essa dúvida quanto à possibilidade da instalação da neurose de transferência procede. Para que a transferência se dê é necessário que o analista seja alguém em quem o paciente possa fazer projeções.

Para a autora a diferença principal entre a análise de crianças e a de adultos estaria na imaturidade do superego infantil. Isso justificaria o papel pedagógico do analista e também sua maneira de conceber a transferência. $O$ analista seria um educador, tendo a responsabilidade de modificar a relação da criança com seus pais à medida que lhe proporciona novas impressões para lidar com as imposições externas.

De fato, para Anna Freud o psicanalista que trabalha com crianças deve levar em conta não somente as questões internas do paciente como também as forças externas que pressionam a criança no seu dia-a-dia.

Assim, as opiniões e as decisões do analista quanto à criança devem ser respeitadas, já que cabe a ele ser não somente analista como também educador, de forma a corrigir uma fase de educação equivocada e de desenvolvimento anormal, dando chance ao seu paciente de ter um desenvolvimento normal. Assim, segundo Anna Freud, para a criança se tratar seus pais teriam que se submeter totalmente ao analista infantil. Quanto à transferência negativa, Anna Freud declara evitá-la ao máximo.

Além da questão pedagógica Anna Freud concebe grande importância para a influência do meio ambiente. Embora esse seu pensamento ela não propôs mudanças estruturais, do modelo biológico, já que continuou a acreditar que a constituição do sujeito acontece partindo de seus instintos.

\section{3 - Melanie Klein: e sua técnica de jogo.}

Klein é a segunda concorrente e sua partida foi disputada em caminhos bem diferentes de Anna Freud.

A teoria kleiniana provocou enorme impacto na Inglaterra e foi uma tendência revolucionária para a sua época. Klein considerava que a análise infantil era um benefício para qualquer criança; mesmo que a criança não 
estivesse muito perturbada emocionalmente, o tratamento evitaria ou dificultaria enfermidades na vida adulta.

Para Klein as crianças apresentam, desde a mais tenra idade, impulsos sexuais e ansiedade, assim como desapontamentos.

As descobertas kleinianas, que foram de grande importancia para a história da prática psicanalítica com crianças, relacionam-se aos primitivos estágios do desenvolvimento, originários do funcionamento da vida mental, ou seja, dizem respeito a tudo quanto existe que não é verbalizado pela criança pequena.

A partir de suas experiências clínicas com crianças, Klein acredita que o que compõe a fonte real das ações e reações dos seres humanos é o mundo interno das relações de objeto e das fantasias inconscientes.

Assim, para a teoria kleiniana a subjetividade se daria por si mesma, isto é, se constituiria internamente. Ao longo dos escritos de Klein verificamos que o indivíduo é representado como uma unidade fechada, com ansiedades e defesas inatas. A estruturação da subjetividade tem claramente origem no mundo interno, com seus objetos internos e suas fantasias inconscientes.

Quanto ao objeto externo de Klein, corresponde à externalização de um elemento psíquico dinâmico interno, e não de fato a um objeto da realidade externa. As relações iniciais do bebê com o mundo externo sofrem influências da experiência do nascimento, considerada como sendo a primeira fonte externa de ansiedade.

Um dos conceitos básicos dessa teoria é a relação objetal que o bebê inicia com a mãe, relação essa que resulta das primeiras experiências da amamentação do bebê e da presença da mãe. A princípio, essa relação se dá com um objeto parcial, uma vez que os impulsos orais-libidinais e orais-destrutivos estão voltados, no início da vida, para o seio da mãe. Em conjunto desses impulsos corresponde à fusão dos instintos de vida e de morte.

Segundo a teoria kleiniana, o material trazido por um paciente ou se refere às relações objetais da criança, que por sua vez podem significar relações com objetos internos e externos.

Para Klein método de atendimento de crianças pelo viés psicanalítico é semelhante ao método clinico da prática com adultos.

Entretanto, Melanie Klein quer mostrar certas diferenças existentes entre a pratica clinica com crianças e a com adultos. A diferença principal marcada pela autora é com relação ao instrumento pelo qual o paciente traz o material para a análise.

É com Melanie Klein que a técnica lúdica toma sua primeira forma. 
"Se nos aproximarmos da criança com a técnica dos adultos, é quase certo que não penetraremos naqueles níveis mais profundos; e não obstante, é disso que depende o sucesso e o valor da análise, tanto para a criança quanto para o adulto. Mas, se tomarmos em consideração as diferenças existentes entre a psicologisa da criança e a psicologia do adulto - o fato de seu inconsciente está em contato mais próximo com o consciente e seus impulsos mais primitivos encontram-se em operação lado a lado com processos mentais altamente complicados - e se captarmos corretamente o modo de expressão da criança, então todos esses inconvenientes e desvantagens desaparecem e descobrimos que podemos esperar realizar uma análise da criança tão profunda e extensa quanto a de um adulto"(1932:32)

Melanie Klein atendia crianças muito pequenas e por conseqüência não falavam e com isso sua prática clínica a colocou em uma situação que contribuiu para o estabelecimento da nova prática.

Para a autora, as crianças neuróticas não toleram bem a realidade, pois tem baixa tolerância as frustrações. Para se protegerem, elas negam a realidade. Assim, a análise com crianças pequenas devem capacitá-las a se adaptarem à realidade, podendo tolerar melhor as frustrações inerentes à vida.

De acordo com Klein, a análise deve fortalecer o ego infantil e ajudá-lo a se desenvolver.

"A interpretação consistente, a resolução gradual das resistências, a referência firme e consistente da transferência, seja ela positiva ou negativa, a situações arcaicas - esses princípios estabelecem e mantêm uma situação analítica correta não menos com a criança do que com o adulto. Uma condição necessária para esse sucesso é o analista abster-se, como faz com pacientes adultos, de exercer qualquer tipo de influência não-analítica e educacional sobre a criança"(1932:35)

Klein(1932:39) explicou que as crianças expressam conteúdos ansiógenos arcaicos através do brincar. Esta é uma representação primária, uma ação que é essencial à expressão da criança. Logo, não há como conduzir uma análise de criança, exclusivamente, por meio de sua fala. Entretanto disse a autora que uma análise só é considerada terminada quando a criança emprega a fala em toda sua capacidade. "A linguagem constitui a ponte para a realidade", complementou, brilhantemente. 


\section{4 - Quando o brincar é dizer}

"A criança é uma pessoa de pouca idade, menino ou menina". Essa é a definição encontrada em um pequeno dicionário de bolso do substantivo feminino 'criança'.

É possível observar que em geral a criança é tida, pelo senso comum, como um ser pequenino e ingênuo. Comentários como "ela não sabe o que esta fazendo pois é apenas uma criança" são corriqueiros.

Quando a palavra é passada à criança há a emergência de um outro tipo de preconceito. Os adultos acreditam que ela não sabe se explicar muito bem, porque lhe faltam palavras, lhe faltam argumentos. Em decorrência, eles acabam por colocar a criança no lugar daquela que não sabe, e de novo passam a tentar deduzir como ela pensa e age.

A abordagem psicanalítica com crianças vai além da concepção cronológica. O objetivo consiste em revelar o que há de específico no infantil e na criança. Além disso a psicanálise enfatiza a importância de se passar a palavra à criança, para que ela nos diga quem ela é e como pensa.

Podemos citar aqui uma precocidade biológica na criança, por assim dizer que a criança esta em pleno desenvolvimento biológico. A psicanálise prefere o termo estrutural ao invés do conceito de desenvolvimento quando se refere ao psicológico. Quando se fala em desenvolvimento facilmente se faz presente o retrato de uma regra, uma lei ou um processo no qual existe um progresso e ao qual cada um tem o dever de cursar.

Cada criança é única e partido dessa afirmação falar em desenvolvimento parece querer colocar uma destituição a subjetividade do pequeno ser. Parece pretender a existência de um ponto a alcançar uma linha de chegada.

A psicanálise fala do conceito de estrutura que é sempre singular e única seguindo os processos específicos, vinculados à história de cada sujeito.

Para a Psicanálise a noção de estrutura, possibilitará captar a criança de uma maneira mais precisa, sem transformá-la em uma peça dos jogos de encaixe das teorias.

O brincar infantil não foge a regra pois ele também é tido como uma banalidade. O adulto costuma dizer " a criança não esta fazendo nada, só brincando".

Ao brincar, a criança não esta fazendo nada e sim esta fazendo muito. Ele não é neutro no sentido de que ele diz algo. É através dele que a criança tenta se haver com seus conflitos e a enxurrada de informações que lhe são postas no dia a dia. A ação lúdica possibilita a criança a tentativa de entender a realidade 
em que esta submetida, ou que lhe é imposta. É simbolizando, fantasiando, atuando, representando, falando ou literalmente brincando os conteúdos que lhe parecem desconexos que ela pode digerir melhor pessoa, conceitos, problematizações, idéias e coisas.

"A reação da pessoa insultada em relação ao trauma só exerce um efeito inteiramente "catártico" se for uma reação adequada - como, por exemplo, a vingança. Mas a linguagem serve de substituta para a ação; com sua ajuda, um afeto pode ser "ab-reagido" quase com a mesma eficácia." (sobre o mecanismo psíquico dos fenômenos histéricos: comunicação preliminar (1893) começo do tópico 2)

Nesta passagem Freud comenta que em determinadas situações traumáticas podem ser ab-reagidas através da linguagem neste trabalho estou considerando o brincar também como no campo da linguagem.

Em Escritores criativos e devaneios, texto de 1907, Freud discute uma correlação entre o ato criativo literário e o brincar da criança colando a hipótese de ambos são determinados pelo desejo. Freud afirma que os jogos infantis, neste momento semelhante ao fantasiar, é uma maneira 'adaptava' onde a criança atua sobre o mundo externo com a tentativa de alterá-lo de forma a fazer uma reconstituição das factualidades. E segundo ele essa necessidade de representação surge através do desejo "(...) de fato por um único desejo - que auxilia o seu desenvolvimento -, o desejo de ser grande e adulto." E ainda:

"não devemos supor que os produtos dessa atividade imaginativa - as diversas fantasias, castelos no ar e devaneios - sejam estereotipados ou inalteráveis. Ao contrário, adaptam-se às impressões mutáveis que o sujeito tem da vida, alterando-se a cada mudança de sua situação e recebendo de cada nova impressão ativa uma espécie de 'carimbo de data de fabricação'. A relação entre a fantasia e o tempo é, em geral, muito importante. É como se ela flutuasse entre três tempos - os três momentos abrangidos pela nossa ideação. $\mathrm{O}$ trabalho mental vincula-se a uma impressão atual, a alguma ocasião motivadora no presente que foi capaz de despertar um dos desejos principais do sujeito. Dali, retrocede à lembrança de uma experiência anterior (geralmente da infância) na qual esse desejo foi realizado, criando uma situação referente ao futuro que representa a realização do desejo. O que se cria então é um devaneio ou fantasia, que encerra traços de sua origem a partir da ocasião que o provocou e a partir da lembrança. Dessa forma o passado, o presente e o futuro são entrelaçados pelo fio do desejo que os une." 
$\mathrm{O}$ desejo $^{3}$ de que aqui falo é aquele desejo inconsciente de que não se pode abrir mão, inalcansável, dirigi-se para o futuro e tem suas raízes no passado.

Em Além do Princípio do Prazer, Freud assinala que a criança não repete apenas ações prazerosas, mas as complicadas e difíceis.

"É claro que em suas brincadeiras as crianças repetem tudo que lhes causou uma grande impressão na vida real, e assim procedendo, ab-reagem a intensidade da impressão, tornando-se, por assim dizer, senhoras da situação. Por outro lado, porém, é óbvio que todas as suas brincadeiras são influenciadas por um desejo que as domina o tempo todo: o desejo de crescer e poder fazer o que as pessoas crescidas fazem. Pode-se também observar que a natureza desagradável de uma experiência nem sempre a torna inapropriada para a brincadeira."

Freud deparou-se com seu neto ainda bebê de vinte meses, jogando um carretel amarrado a um barbante para fora do berço fazendo com que este desaparecesse de seu campo visual, e em seguida, puxando-o de volta. Cada vez que ele jogava e o carretel desaparecia ele pronunciava o fonema "Fort" e quando puxava de volta, o fonema "Da"; que eram apenas balbucios para um bebê daquela idade. Mas, Freud percebe que aquele jogo e fonemas eram, muito mais do que uma simples brincadeira ou balbucios para um bebê daquela idade, e à partir destas observações fez seus primeiros escritos sobre o brincar.

Sua observação fundamental do jogo do "Fort-Da", como ele nomeou, foi que este era um jogo de presença-ausência (o carretel sumia e depois aparecia) e que possibilitava a criança construir sua compreensão para a ausência de seu objeto de amor - a mãe.

Nesse exemplo Freudiano é possível verificar a presente repetição dos balbucios simultaneamente com o sua ação de jogar o carretel possibilitando uma articulação do seu brincar com a palavra - fonemas "Fort"(ausência) e "Da"(presença).

A criança no jogo, elabora uma situação penosa como esta, e assim, também se inscreve no mundo da linguagem. A atitude do neto de Freud pode ser considerada como uma tentativa independente de se haver com a realidade que lhe estava sendo imposta.

(mais além do principio do prazer, inicio do tópico II)

\footnotetext{
${ }^{3}$ Laplanche e Pontalis definem o conceito freudiano de desejo como: “ um dos pólos do conflito defensivo. O desejo inconsciente tende a realizar-se restabelecendo, segundo as leis do processo primário, os sinais ligados às primeiras vivências de satisfação.
} 
"No início, achava-se numa situação passiva, era dominada pela experiência; repetindo-a, porém, por mais desagradável que fosse, como jogo, assumia papel ativo. Esses esforços podem ser atribuídos a um instinto de dominação que atuava independentemente de a lembrança em si mesma ser agradável ou não. Mas uma outra interpretação ainda pode ser tentada. Jogar longe o objeto, de maneira a que fosse 'embora', poderia satisfazer um impulso da criança, suprimido na vida real, de vingar-se da mãe por afastar-se dela. (...) Quando a criança passa da passividade da experiência para a atividade do jogo, transfere a experiência desagradável para um de seus companheiros de brincadeira e, dessa maneira, vinga-se num substituto."

Sejam as repetições prazerosas ou aquelas desprazerosas o que Freud chegou a concluir em seus estudos sobre o brincar é que os símbolos, as imagens, os objetos não são neutros. Eles estão erotizados e é essa a condição para que a repetição ocorra.

Podemos considerar Freud, como já foi dito anteriormente neste trabalho, como o precursor da técnica do brincar, instituida na psicanálise com crianças por Melanie Klein.

Partido do estudo dos mecanismos psicológicos envolvidos na ação lúdica, explicado por Freud através do jogo "Fort-Da". Mais freud não parou apenas nesta explicação e é possível encontrar em sua obra discussões acerca da prática de uma técnica lúdica e sua importância. A presença de uma capacidade de expressão verbal ou pré-verbal, bem como a possibilidade de associação em crianças pequenas e a sua utilização foram também abordadas por Freud.

Encontramos um exemplo disso num pequeno relato em que Freud faz uma descrição do que chama um "ato sintomático" de um paciente seu, de menos de treze anos de idade, em tratamento analítico. Freud contava a história de um mito para a criança na sessão. A criança, por sua vez, brincava com um pedaço de miolo de pão, manipulando-o e criando personagens. Durante o seu relato do mito, Freud usou a expressão "em silêncio cortou", e conta o seguinte:

"Enquanto eu falava, o menino parou de amassar (o miolo de pão) e quando alcancei as palavras "em silêncio cortou", o menino fez um movimento rápido como um raio e arrancou a cabeça do seu pequeno homem (de miolo de pão). Portanto, ele me entendera e notara que havia sido entendido por mim.”(1901:FREUD)

Freud indica nessa situação e na sua forma de interpretá-la exatamente o que viria a ser um exemplo da técnica de brincar na psicanálise de criança. Percebemos aí que não só a criança se expressa através da brincadeira, mas 
através da brincadeira responde a uma interpretação. Estavam estabelecidas as bases de um diálogo psicanalítico.

O jogo permite que a criança demostre seus conflitos e possibilita sua interpretação.

Com o pequeno Hans Freud se utilizou de interpretações de sonhos, fantasias e jogos que foram os três veículos com os quais o menino se utilizou para se expressar. Para Aberastury "O maior interesse deste caso, considerando-o como ponto de partida da técnica da psicanálise de crianças, é o de mostrar a eficácia das interpretações e as suas conseqüências."(1979:31)

Para Melanie Klein "A criança expressa suas fantasias, seus desejos e suas experiências reais de um modo simbólico, através de brincadeiras e jogos"(1932:30). Ela relata que as crianças se expressam nos jogos como os adultos nos sonhos. Assim, a análise deve considerar os jogos e as brincadeiras como uma "linguagem dos sonhos". Todos os elementos que a criança apresenta ao brincar são as suas associações.

"O brincar é o meio mais importante de expressão das crianças", e além de trazer elementos nas brincadeiras, as crianças falam enquanto estão brincando. “...Enquanto brinca, a criança também conversa e diz toda sorte de coisas, que tem o mesmo valor de genuínas associações”, esclareceu Klein(1932:31).

Para Klein ao brincar as crianças expressavam suas fantasia, ansiedades e angústias. Tinha, então o processo lúdico como a possibilidade de expressão do mundo interno da criança. Assim como o adulto fala a criança brinca.

Assim, para Klein cabia ao analista interpretar a brincadeira para ter acesso ao inconsciente da criança.

O brincar é um dos objetos fundamentais da teoria Kleiniana e sua função no processo analítico é constantemente discutido.

Através de suas experiências clínicas Klein acreditava que o brincar, no seting analítico, possibilita a criança vivênciar e vencer realidades dolorosas e medos com o ato de esteriorizá-las. A função do jogo é de fazer o papel da ponte entre a fantasia e a realidade que possibilita a elaboração, por parte da criança e com a ajuda da interpretação do analista, de situações traumáticas para o ego, cumprindo um movimento catártico e de assimilação dos fatos presenciados.

\section{Conclusão}

Como já exposto na introdução deste trabalho de várias perguntas é que resultou a realização deste trabalho. A proposta era de restringir a curiosidade e se atentar para uma pergunta a qual o tamanho desse trabalho comportasse. Mesmo com todo esse cuidado a elaboração do projeto foi muito difícil. E com toda a 
restrição a pergunta restante parecia imensa e tortuosa. E em relação a prática clínica com crianças na abordagem psicanalista, poucas foram respondidas.

Isso então é só o começo de um longo e vasto caminho a percorrer em direção às respostas que talvez nunca sejam alcançadas.

Foi de grande utilidade entender um pouco de onde veio a psicanálise com crianças e conhecer minimamente seu percurso. Com relação a técnica do brincar a conclusão que melhor me surge a cabeça no momento é: Falta-me a prática! E com ela quem sabe a elaboração deste trabalho seria mais fácil.

Maria Luiza D'Ávila Pereira, em sua tese de mestrado, consegue letrar muito bem meus sentimento quando, após um angustiado período pré-produção científica deduz:

“eu acho que a clinica é a única saída que temos para formular uma teoria, que, no final, é de autoria do paciente e não nossa. A nós, clínicos, cabe construir, apenas. Pegar todos os tijolos que nos são dados, numerados, e organizá-los; levantar os alicerces que sustentam as estruturas que já existem a priori de nós" Pereira (p 26)

Com essas conclusões a autora, na introdução de sua tese de mestrado, nos coloca a sua angústia e insatisfação em apenas percorrer o campo teórico de seu objeto de estudo e a necessidade de se voltar para sua clínica.

Posso concluir que diferentemente da clinica com adultos uma das especificidades da psicanálise com crianças é relativa ao método empregado para sua realização: o brincar. Nesta perspectiva propõe que a experiência psicanalítica na infância se processa através da articulação do brincar com a verbalização, tanto no que diz respeito à produção discursiva do paciente, quanto no que se refere à interpretação do analista.

\section{Referências Bibliográficas}

ABERASTURY, A. (1979). Psicanálise da criança . Porto Alegre: Artes Médicas, 1982.

FERREIRA, A. B. de H. Minidicionário da língua portuguesa: Aurélio. Rio de Janeiro: Nova Fronteira, 1985.

FOUCAUlT, M.. A psicologia de 1850 a 1950. Problematização do sujeito;

psicologia, psiquiatria e psicanálise. Forense, Rio de Janeiro, 1999.

FREUD, A. O tratamento psicanalítico de crianças (1926). Rio de Janeiro: Imago, 1977. 
1971.

. Infância normal e patológica(1965). Rio de Janeiro: Zahar ,

FREUD, S.. Análise de uma fobia em um menino de cinco anos (1909). In: .Edição Standard Brasileira das Obras Psicológicas Completas de Sigmund Freud. Imago, Rio de Janeiro, 1996, v.XII.

FREUD, S.. A história do movimento psicanalítico (1914). In: .Edição

Standard Brasileira das Obras Psicológicas Completas de Sigmund Freud. Imago, Rio de Janeiro, 1996, v.XII.

. Além do Princípio de Prazer (1920). In: .Edição

Standard Brasileira das Obras Psicológicas Completas de Sigmund Freud. Imago, Rio de Janeiro, 1996, v. XVIII.

. Psicopatologia da vida cotidiana (1901). In: .Edição

Standard Brasileira das Obras Psicológicas Completas de Sigmund Freud. Imago, Rio de Janeiro, 1996, v. XVIII.

- Sobre o mecanismo psíquico dos fenômenos histéricos: Comunicação preliminar (1893)In: .Edição Standard Brasileira das

Obras Psicológicas Completas de Sigmund Freud. Imago, Rio de Janeiro, 1996, v. XVIII.

LAPLANCHE, J. Vocabulário da Psicanálise. $3^{\text {a }}$ edição. Martins Fontes, São Paulo, 1998.

KLEIN, M. (1932) Psicanálise da Criança . 2 a ed., São Paulo: Ed Mestre Jou, 1975.

PEREIRA, M.L.D. Da angústia ou de quando indicar análise a uma criança. Curitiba: Editora da UFPR, 1990. 